\title{
Gene activation regresses atherosclerosis, promotes health, and enhances longevity
}

Pauli V Luoma

\begin{abstract}
Background: Lifestyle factors and pharmacological compounds activate genetic mechanisms that influence the development of atherosclerotic and other diseases. This article reviews studies on natural and pharmacological gene activation that promotes health and enhances longevity.

Results: Living habits including healthy diet and regular physical activity, and pharmacotherapy, upregulate genes encoding enzymes and apolipoprotein and ATP-binding cassette transporters, acting in metabolic processes that promote health and increase survival. Cytochrome P450-enzymes, physiological factors in maintaining cholesterol homeostasis, generate oxysterols for the elimination of surplus cholesterol. Hepatic CTP:phosphocholine cytidylyltransferase- $\alpha$ is an important regulator of plasma $\mathrm{HDL}-\mathrm{C}$ level. Gene-activators produce plasma lipoprotein profile, high $\mathrm{HDL}-\mathrm{C}, \mathrm{HDL}_{2}-\mathrm{C}$ and $\mathrm{HDL}-\mathrm{C} /$ cholesterol ratio, which is typical of low risk of atherosclerotic disease, and also of exceptional longevity together with reduced prevalence of cardiovascular, metabolic and other diseases. High HDL contributes to protection against inflammation, oxidation and thrombosis, and associates with good cognitive function in very old people. Avoiding unhealthy stress and managing it properly promotes health and increases life expectancy.

Conclusions: Healthy living habits and gene-activating xenobiotics upregulate mechanisms that produce lipoprotein pattern typical of very old people and enhance longevity. Lipoprotein metabolism and large $\mathrm{HDL}_{2}$ associate with the process of living a very long life. Major future goals for health promotion are the improving of commitment to both wise lifestyle choices and drug therapy, and further the developing of new and more effective and well tolerated drugs and treatments.
\end{abstract}

\section{Introduction}

It is common knowledge that diet, exercise and less stress are likely to enhance longevity, but the mechanisms are not well known. Chronic stress can lead to behavioral and somatic disorders such as anxiety, depression, obesity, dyslipidemia, metabolic syndrome, and atherosclerosis with its cardiovascular sequalae, premature cardiovascular disease and death [1]. On the other hand, prudent diet and regular physical activity, and pharmacological compounds, have metabolic effects that reduce the risk of cardiovascular and other diseases. Atherosclerotic cardiovascular disease is the leading global health problem as assessed by mortality [2], and the research focusing on the atherosclerotic vascular process is of particular importance for health promotion.

*Correspondence: pauli.luoma@fimnet.fi

1 Institute of Biomedicine, Pharmacology, University of Helsinki, Finland Full list of author information is available at the end of the article
Population studies performed in the 1970s identified high plasma apolipoprotein AI (apo AI) and HDL cholesterol (HDL-C) levels as powerful indicators of a low risk of coronary heart disease (CHD) and cerebrovascular disease $[3,4]$, whereas high apo B and LDL-C indicate an increased risk of CHD and death. The close relation of the major risk factors to cardiovascular diseases led to great continuing interest in agents with potential to raise apo AI and HDL-C and reduce apo B and LDL-C. Clinical studies soon revealed that drugs which induce protein synthesis increase hepatic cytochrome P450 activity and plasma apo A1 and HDL-C and the HDL-C/cholesterol ratio $[5,6]$. The inducing agents are gene-activators that can also upregulate hepatic LDL receptor (LDLR) gene and reduce plasma LDL-C [6,7]. These compounds influence cholesterol homeostasis also in other tissues including vasculature, intestine and the brain. A number of physiological and pharmacological compounds act, via 
the activation of enzyme, receptor and transporter genes, against the atherosclerotic process, whereas mutations in the genes can promote atherogenesis. The ability to control the expression of these genes provides a possibility to influence the development of cardiovascular disease and to extend lifespan. Investigations performed in the last few years focusing on this possibility have resulted in significant positive results. This article reviews studies on natural and pharmacological gene activation that regresses atherosclerosis, reduces the incidence of cardiovascular and other diseases, and enhances longevity.

\section{Liver and plasma lipids and proteins and gene- activation}

Both endogenous and exogenous factors act on the risk and the development of atherosclerosis. An endogenous induction of apo AI synthesis resulting in high plasma apo $\mathrm{AI}$ and HDL-C concentration has been identified as a cause of familial hyperalphalipoproteinemia which is characterized by a low death rate from CHD and prolonged life expectancy [8], while a low apo AI synthesis rate leads to hypoalphalipoproteinemia [9] that promotes atherogenesis. Similarly, drugs which induce hepatic protein and phospholipid synthesis and P450 activity, could increase plasma apo AI and HDL-C [10] (Figure 1) and the HDL-C/cholesterol ratio [11] that reflects an enhanced hepatic secretion of apo AI-phospholipid complexes. Corresponding to these effects, an overexpression of human apo AI transgene prevents atherogenesis [12] and an infusion of apo AI-phospholipid complexes in humans regresses atherosclerosis [13]. The liver produces the majority of HDL phospholipids, phosphatidylcholine (PC) being the primary phospholipid in cellular membranes and plasma lipoproteins [14]. Hepatic CTP: phosphocholine cytidylyltransferase- $\alpha$ (CCT $\alpha)$ is the key enzyme in the synthesis of $\mathrm{PC}$ and an important regulator of plasma HDL-C level (next chapter).

\section{Enzymes, atheroprotection and atherosclerosis}

A number of enzymes participate in processes that protect arteries from atherosclerosis, including P450enzymes belonging to different cytochrome (CYP) classes, CCT $\alpha$, sirtuin 1(SIRT1) and paraoxonase-1 (PON1).

P450-enzymes have in addition to recognized pharmacological and toxicological functions, important physiological functions in the control of cellular homeostasis. P450-isoenzymes such as CYP7A1, CYP27A1 and CYP46A1 are natural regulators of cholesterol homeostasis which hydroxylate it to oxysterols (OHCs) $[15,16]$. CYP7A1 is essential for the conversion of cholesterol to $7 \alpha-\mathrm{OHC}$ and as the key rate-limiting enzyme in the synthesis of bile acids. A mutation in CYP7A1gene can reduce bile acid synthesis, increase hepatic cholesterol, and present as a phenotype reminiscent of that in familial hypercholesterolemia (FHC) associated with premature atherosclerotic disease [17]. Correspondingly, a low rate of bile acid synthesis in FHC predicts enhanced mortality from CHD [18], and bile acid binding and CYP7A1 inducing resin therapy reduces cardiovascular mortality [19]. Side-chain OHCs such as 27OHC, $24 \mathrm{SOHC}$ and $25 \mathrm{OHC}$ generated by CYP27A1, CYP46A1 and cholesterol 25-hydroxylase, respectively, are signal mediators that have been identified as activators of liver $\mathrm{X}$ receptors (LXRs) both in vitro and vivo [20-22]. The OHCs influence cellular cholesterol homeostasis by serving as ligands for LXRs that upregulate genes acting in cholesterol elimination pathways, and through the suppression of SREBP (sterol regulatory element binding protein) maturation and promoting the degradation of hydroxymethylglutaryl CoA reductase (HMGCOAR), the rate-limiting enzyme of cholesterol synthesis [23]. CYP46A1 influences cholesterol homeostasis in the brain by converting it to $24 \mathrm{SOHC}$, which readily passes the blood brain barrier and may also as a ligand for LXR promote the efflux of cholesterol. CYP3A4, a key enzyme in the metabolism of xenobiotics also affects the fate of cholesterol. CYP51A1 is the only P450 enzyme participating in cholesterol synthesis. The synthesis generates metabolites including, 24S,25 epoxycholesterol which suppresses SREBP-2 process and HMGCOAR activity, and may as a ligand for LXR prevent cholesterol accumulation [24].

Cardiovascular P450s include enzymes belonging to several CYP families [25-27]. Many of them generate eicosanoids that have important functions in vascular physiology. The CYP2C and 2J epoxygenases metabolize arachidonic acid to eicosanoids, epoxyeicosatrienoic acids (EETs) which are mediators in vascular signaling processes. CYP4 $\omega$-hydroxylases convert EETs to dihydroxyeicosatrienoic acids (DHETs). Both EETs and DHETs activate peroxisome proliferator-activated receptors (PPARs), which have a role in vascular functions [26]. EETs are vasodilating compounds which inhibit inflammatory response, promote fibrinolysis and may function as endogenous antiatherogenic compounds [25,27]. A mutation in CYP2J2 gene has been linked to reduced plasma EET concentrations and increased risk of CHD [27]. CYP4A and CYP4F enzymes convert arachidonic acid to 20-hydroxy - eicosatetraenoic acid (20HETE) [26]. Vascular $\omega$-hydroxylases further metabolize 20HETE to 20-carboxy-arachidonic acids which also activate PPAR $\alpha$ and PPAR $\gamma$ receptors [27]. Several drugs including statins and fibrates are PPAR activators $[25,28]$.

$\mathrm{CCT} \alpha$, the rate-limiting enzyme in the synthesis of PC, has been identified as a key player in maintaining plasma HDL-C levels [14]. CCT $\alpha$ knock-out mice show reduced hepatic PC content as well as ABCA1 (ATP-binding cassette $\mathrm{A} 1$ ) expression in hepatocytes and marked decrease 


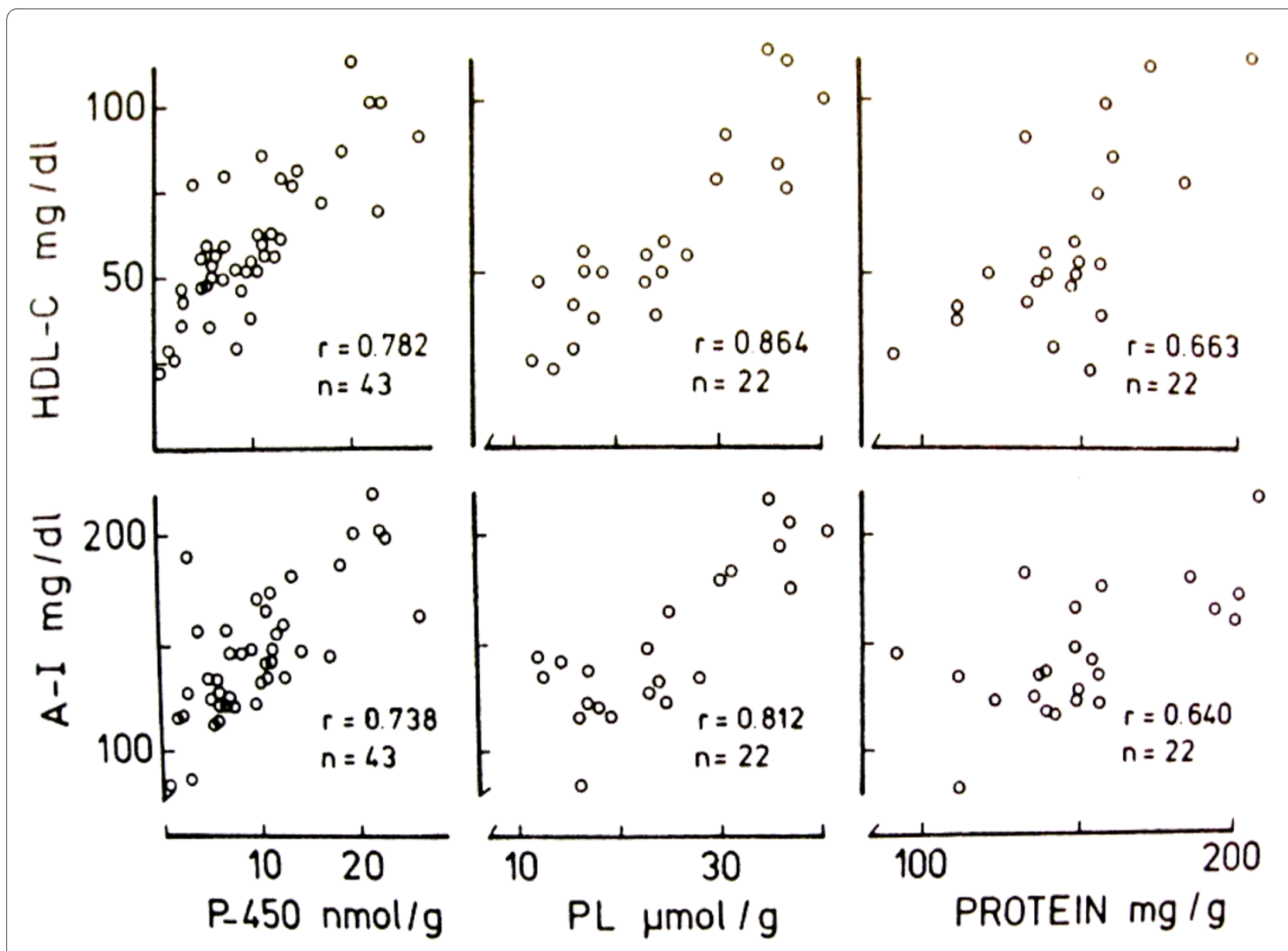

Figure 1 Relation of plasma HDL-C and apolipoprotein Al to liver cytochrome P450, phospholipid (PL) and protein in man. Some patients were treated with gene-activating drugs (Luoma PV el al, Lancet. 1982, 1:625).

in HDL-C [14]. Cholesterol and PC efflux to apo AI is impaired by CCT $\alpha$ deficiency in the hepatocytes [14]. Adenoviral delivery of CCT $\alpha$ to knock-out mice restored PC mass in knock-out livers, increased hepatic ABCA1 levels, and normalized HDL-C levels in vivo [14]. CCT $\alpha$ is also necessary for protection against cholesterolinduced cell death [14]. An elevation of cellular cholesterol induces the generation of side-chain OHCs that upregulate CCT $\alpha$ and PC synthesis [29]. Relatively low concentrations of OHCs increase CCT $\alpha$ activity and PC synthesis in adose-dependent manner.The $\mathrm{OHCs}$ could directly act on CCT $\alpha$ and increase PC synthesis, and thereby act against cholesterol toxicity [29]. The study of Gehrig et al. showed that direct activation of CCT $\alpha$ by $\mathrm{OHCs}$ is a potential mechanism to maintain sterol/phospholipid content of membranes within normal boundaries [29].

SIRT1 is a nicotinamide adenine dinucleotide-dependent deacetylase that regulates physiological processes including systemic and hepatic glucose, lipid and cholesterol homeostasis [30,31]. SIRT1 has broad biological functions in growth regulation, stress response, tumorigenesis, endocrine signaling, and extended lifespan [32]. The enzyme is connected to important metabolic changes and regulatory proteins in response to caloric restriction. Fasting increases SIRT1 activity that reduces insulin secretion and increases insulin sensitivity, stress resistance and cell survival [32]. Hepatic SIRT1 controls the expression of genes involved in cholesterol metabolic pathways [30]. It upregulates, via LXR activation, ABCA1 transporter and cellular cholesterol efflux to apo AI and HDL formation [31]. The expression of ABCA1 is reduced in SIRT1 knockout mice, resulting in defective cholesterol efflux and lower HDL-C levels, and blunted response to LXR agonists [31]. SIRT1, which extends life span in several species including mammals has emerged as a drug development target for treating age-dependent diseases [31-33].

PON1, an enzyme with antioxidant function primarily synthesized in the liver, is associated with HDL in the subintimal space of the artery. HDL together with PON1 is ideally positioned to protect LDL from oxidative modi- 
fication in the arterial wall and to prevent the processes that initiate atherogenesis. Lifestyle factors, a number of diseases, drugs and nonpharmacologic factors may influence PONI 1 activity (reviewed in ref. 34). An atherogenic diet and smoking decrease PON1 activity, and it is low in patients with surgical menopause, type 1 diabetics with elevated blood glucose, chronic hepatitis and cirrhosis, rheumatoid arthritis and Alzheimer's disease. On the other hand, exercise, moderate alcohol consumption, hormone replacement therapy, and the use of statins, fibrates or aspirin associates with increased PON1 activity [34]. Patients with a mutated PON1 gene show accelerated atherosclerosis as assessed by carotid intimamedia thickness (IMT) [35], and two prospective studies associated low PON1 activity with high incidence of major cardiovascular events [34]. An overexpression of human PON1 in mouse models of atherosclerosis decreased aortic lesion size [34].

\section{Receptors, transcription factors, and risk factors}

Nuclear receptors regulate the expression of genes encoding enzymes, transporters and other proteins involved in metabolic homeostasis [36]. LXR receptors (LXR $\alpha$ and LXR $\beta$ ) function as cholesterol sensors and mediators that act on genes involved in the absorption, efflux, and transport of cholesterol to the liver, bile acid synthesis, biliary sterol secretion, and the synthesis of nascent HDL [37]. LXR activation downregulates intestinal Niemann-Pick C1 like transporter which is critical for cholesterol absorption [38], and has similar effect on CYP51A1 and squalene synthase, key enzymes in the synthesis of cholesterol [39]. PPAR receptors, PPAR $\alpha$, PPAR $\gamma$ and PPAR $\delta$, control lipid and glucose metabolism, as well as depress the inflammatory response in various tissues and cells including macrophages and monocytes [36,40]. PXR is a regulator of xenobiotic metabolizing P450 enzymes which hydroxylate cholesterol and its metabolites [41]. PXR also is a positive regulator of CYP27A1 in human intestinal cells and could via LXR $\alpha$ activation stimulate cholesterol efflux from intestinal cells to apo AI and HDL formation [42].

SREBPs are transcription factors that activategenes dedicated to the synthesis and uptake of cholesterol, fatty acids, phospholipids and triglycerides [7]. SREBP-2 preferentially activates genes involved in the synthesis of cholesterol. LDLR is a membrane cholesterol transporter that mediates cellular uptake of LDL-C. A depletion of hepatic cholesterol activates SREBP processing that induces the expression of LDLR. Scavenger receptor B1 (SR-B1) is a cell-surface HDL receptor expressed in several tissues including the liver [43]. It facilitates cholesterol efflux from peripheral cells to HDL and mediates the hepatic uptake and biliary secretion of cholesterol. Studies using
SR-B1- transgenic and - deficient mouse models have established the antiatherogenic activity of SR-B1 in vivo.

\section{ABC-transporters, apolipoproteins, HDL and cholesterol}

$\mathrm{ABC}$ transporters have a major role in the control of whole-body cholesterol homeostasis [44]. ABCA1 regulates the rate-limiting step in the biogenesis of HDL particles by mediating the efflux of cholesterol and phospholipids across cellular membranes [44-46]. Hepatic ABCA1 is the main factor in the generation of HDL-C levels in the circulation. ABCG1 which is expressed in several tissues facilitates cholesterol efflux to HDL. ABCG4 transporter acts on cholesterol in the brain, and ABCG5 and ABCG8 in the liver and intestine. ABCA7 may mediate HDL assembly and generate cholesterol-poor HDL [47]. Apo AI, the predominant protein constituent of HDL, is produced by liver and intestine. It removes cellular cholesterol and phospholipids transported to plasma membrane [44]. Lipid-free and lipidpoor apo AI are the key molecules in the initiation of HDL formation. Apo AI is an activator of lecithin: cholesterol acyltransferse (LCAT) and a ligand for the binding of HDL to SRB1. Other apolipoproteins including AII, E, $\mathrm{CI}, \mathrm{CII}, \mathrm{CIII}$, and AIV also serve in ABCA1-mediated cholesterol efflux [44].

\section{Genes, familiality, risk factors and lifespan}

The contribution of genetic factors to life expectancy has become increasingly important at advanced ages [48]. Exceptional longevity is also familial. People in the most advanced decades of life, especially centenarians, possess lipoprotein profile that is typical of low risk of atherosclerotic disease. They have high HDL-C and $\mathrm{HDL}_{2}-\mathrm{C}$ [49], and also high HDL-C/cholesterol ratio $[49,50]$ and low cholesterol and LDL-C as compared to septuagenarians [50,51]. Large HDL, i.e. the subclass $\mathrm{HDL}_{2}$, and large LDL have been identified as typical lipoproteins of exceptional longevity [52]. The predominance of large lipid-rich $\mathrm{HDL}_{2}$ subclass is the most reproducible phenotype among very old people [49], who also have reduced prevalence of cardiovascular diseases, hypertension, metabolic syndrome and diabetes mellitus $[48,49,52]$. The offsprings of very old people also have lower prevalence of cardiovascular disease and cardiovascular risk factors and a greater survival rate when compared to the controls who had one parent die at average life expectancy $[53,54]$.

\section{Diet - gene activation, risk factors, and health effects}

Dietary factors have significant metabolic and health effects. Diet constituents such as soy proteins and alcohol induce the expression of apo AI gene and raise HDL-C, 
and vitamins, e.g. vitamin $C$ and $E$ might have similar effect [55]. Vitamin $B_{3}$ or niacin has recently been shown to increase apo AI production in man [56] and vitamin A deritative 9-cis retinoid acid to upregulate apo AI gene expression in HepG2 cells [55,57]. Weight control by a low calorie diet with adequate nutrition has positive effects. It increases insulin sensitivity, stress resistance, and cardioprotection, and decreases insulin secretion, fat storage and glycolysis [32]. The activating effect of the diet on SIRT1 could contribute to atheroprotection. The enzyme is positive regulator of LXR and cholesterol efflux via HDL formation. SIRT1 overexpression in fasted state could also induce hepatic CYP7A1 and decrease hepatic cholesterol content $[30,33]$ that upegulates LDLR pathway and reduces plasma LDL-C.

Natural mechanisms protect cells from harmful effects of the diet. An atherogenic cholesterol-rich diet upregulates hepatic P450-enzymes that reduce cholesterol toxicity by inducing its catabolism to OHCs and elimination [58], and an activation of hepatic LXR $\alpha$ to protects animals from atherosclerosis of dietary origin [59]. Fatty acids and eicosanoids are endogenous activators of PPARs that also respond to high fat diet and act against atherogenic dyslipidemia and promote reverse cholesterol transport [36]. PXR mediates the activation of hepatic cholesterol metabolizing P450-enzymes and thereby protects against acute toxicity caused by a highcholesterol diet [41].

Randomized trials show that modest consumption of oily fish, 1 to 2 servings per week, reduces CHD mortality by more than one third, with $17 \%$ reduction in total mortality, and indicate consistent and substantial reductions in cardiovascular risk related to lower trans fat consumption, consumption of whole grains, legumes, and cereal fiber, and consumption of fruits and vegetables [60]. Great improvements can be reached by promoting Mediterranian-type of diet [61] which is characterized by high intake of olive oil, vegetables, legumes, fruits nuts and cereals, a moderately high intake of fish, but low intake of saturated lipids, meat and poultry, and a regular but moderate intake of ethanol, primarily in the form of wine and generally during meals [62]. The people on Mediterranian diet have a favorable cardiovascular risk factor profile, low systolic and diastolic blood pressure, and fasting blood glucose and insulin levels [63], together with low mortality rate from CHD, cardiovascular disease, cancer, and also all-cause mortality [62-64].

\section{Physical activity - metabolic and health effects}

Regular physical activity has multiple metabolic and health effects (Table 1) [60]. It reduces plasma LDL-C, cholesterol and triglycerides, and raises $\mathrm{HDL}-\mathrm{C}$ and $\mathrm{HDL}_{2}-\mathrm{C}$ [65]. It also upregulates LXR $\alpha$, PPAR $\gamma$, and scav-
Table 1: Effects of regular aerobic physical activity ${ }^{1}$

\begin{tabular}{cl}
\hline $\begin{array}{c}\text { Upregulation } \\
\text { Receptors } \\
\text { Enzymes } \\
\text { Transporters }\end{array}$ & LXRa, PPARY SR-B1, LDLR, CD36 \\
Change in risk factor & ABCA1, ABCG1, Apo Al \\
Increase & \\
Decrease & Apo Al, HDL-C, HDL $-\mathrm{C}$ \\
Improvement & LDL-C, cholesterol, triglycerides \\
& cellular cholesterol efflux \\
& peak pulmonary oxygen uptake \\
& glucose - insulin homeostasis \\
& weight control \\
& psychological wellbeing \\
Lowering & blood pressure \\
Decrease & CHD, cardiovascular, cancer and \\
& total mortality \\
\hline
\end{tabular}

${ }^{1}$ The list of abbreviations precedes the reference list.

enger receptor CD36 (cluster of differentiation 36) that leads to an increased uptake of atherogenic oxidized LDL, and ABCA1 and ABCG1 in leucocytes [66]. Endurancetrained men show high $\mathrm{VO}_{2} \max$ (peak pulmonary oxygen uptake) together with high HDL-C, apo AI, and increased plasma LCAT activity and cholesterol efflux from macrophages compared with normally active men $[67,68]$. The increased LCAT activity leads to an increased production of $\mathrm{HDL}_{2}$ [69]. Experimental studies also show that endurance exercise upregulates hepatic P450, LDLR and SR-B1, increases the catabolism of cholesterol to bile acids, and prevents gallstone formation [70]. In addition, regular physical activity helps maintaining weight control, improves glucose - insulin homeostasis, lowers blood pressure, and improves psychological wellbeing [60]. It also reduces, in proportion to overall physical activity, the mortality form CHD, cardiovascular disease, and cancer, and also from any cause [71,72]. Regular physical exercise also facilitates smoking cessation that reduces total mortality by approximately one third [60].

\section{Stress - mediators and diseases}

The main central molecular mediators of the stress system are corticotropin-releasing hormone, arginine vasopressin and norepinephrine, and key peripheral mediators are corticotropin, cortisol, arginine vasopressin, norepinephrine, epinephrine and interleukin-6 [1]. The stress system is activated in a coordinated fashion during acute stress influencing central and peripheral functions that are important for adaptation and survival. Chronic activation of stress system is associated with many negative manifestations. It can lead to common 
mental and somatic disorders such as anxiety, depression, and development of obesity and metabolic syndrome with insulin resistance, dyslipidemia, arterial hypertension, type 2 diabetes, and atherosclerosis ultimately resulting in premature cardiovascular disease and death [1].

\section{Studies on model organisms and longevity}

Experiments in model organisms such as Caenorhabditis (C) elegans and Drosophila (D) melanogaster have identified a number of potential genetic mechanisms which can increase survival. The genes involved include daf-2, an insulin receptor-like gene, and daf-12, a nuclear receptor gene in C. elegans, and catalase and suproxide dismutase genes in D. melanogaster. Experiments in these organisms have demonstrated that changes in genes can markedly increase lifespan, but to what extent they explain variation in humans is still uncertain [73]. The environments in which the genes come to expression in these species and humans are markedly different, and caution should be taken in extrapolating the relevance of results on genetic variation in model organisms to the human situation [73].

\section{Xenobiotic gene-activators - antiatherogenic effects}

A number of xenobiotics are gene-activators that have antiatherosclerotic actions. Several of them, but not all, are P450 inducers.The major effects of statins, niacin, fibrates and cholestyramine, important drugs for treatment of dyslipidemias, are presented here. Recent studies have contributed significant positive results. Other compounds with beneficial effects include angiotensin-converting enzyme inhibitors (ACEIs), calcium channel blockers (CCBs), angiotensin receptor blockers (ARBs), glitazones, anticonvulsants, retinoids and alcohol [74].

Statins inhibit HMGCOAR and cholesterol synthesis and decrease hepatic cholesterol that activates SREBP processing and upregulation of LDLRs on the surface of liver cells and reduces plasma LDL-C [7]. The drugs also induce PPAR $\alpha$ and apo AI synthesis in liver cells [58] and raise plasma apo AI, HDL-C and the subfraction $\mathrm{HDL}_{2}-\mathrm{C}$ [75]. Statins also stimulate CYP4 $\omega$-hydroxylases in human liver microsomes and CYP2 epoxygenase in native endothelial cells which generate PPAR-activating eicosanoids $[25,28]$. The drugs upregulate via PPAR activation LXR, ABCA1 and ABCG1 genes in cholesterolloaded macrophages and hepatocytes, and promote cholesterol efflux to apo AI and HDL [58]. Statins also induce, through SREBP-2 activation, CYP4F2 [76] and ABCA1 [77] genes in human hepatocytes.

Niacin, which is not a P450-inducer, has recently been shown to stimulate apo AI production in patients with combined hyperlipidemia [56]. The drug also upregulates PPAR $\gamma, \mathrm{LXR} \alpha$ and ABCA1 genes and promotes HDLdependent cholesterol efflux from monocytoid cells [78], and raises apo AI and HDL-C, particularly $\mathrm{HDL}_{2}-\mathrm{C}$ [79], and reduces LDL-C and triglycerides. Statin - niacin combination is more effective than monotherapy in raising $\mathrm{HDL}-\mathrm{C}$ and $\mathrm{HDL}_{2}-\mathrm{C}$ and reducing LDL-C and triglycerides [80]. Fibrates, PPAR $\alpha$ agonists which induce P450s including $\omega$-hydroxylases and apo AI synthesis [58], raise plasma apo AI and HDL-C and reduce LDL-C and triglycerides. Fibrate-caused PPAR $\alpha$ activation upregulates LXR, SR-B1 and ABCA1 genes and promotes apo AI-mediated cholesterol efflux [40]. Cholestyramine binds bile acids, induces CYP7A1 and depletes cholesterol in hepatocytes, and increases LDL-C elimination via the upregulated LDLR pathway, and also induces apo AI synthesis and raises plasma apo $\mathrm{AI}$ and $\mathrm{HDL}_{2}-\mathrm{C}$ subfraction [81]. The combination of resin and statin is effective in reducing circulating cholesterol levels [82].

\section{Xenobiotic gene-activators, diseases and longevity}

Several xenobiotic gene-activators prevent or regress atherosclerosis and increase survival. Recent studies have contributed significant positive results. The major effects of statins, niacin, fibrates, cholestyramine, ARBs, ACEIs and CCBs are presented here. Other compounds including pioglitazone, anticonvulsants and alcohol also have positive effects [74].

Statins including pitavastatin [83], fluvastatin [84], pravastatin [85], rosuvastatin, atorvastatin and simvastatin [58], regress coronary atherosclerosis as assessed by intravascular ultrasonography (IVUS) technique. Statin therapy that caused a moderate rise in HDL-C level together with significant LDL-C lowering was particularly effective in regressing atherosclerotic plaque [86]. The statins also reduce both nonfatal and fatal cardiovascular events, and all-cause mortality [58]. The drugs improved survival rate also of people with cardiovascular risk factors but without cardiovascular disease [87], and population studies linked statin therapy with reduced mortality rate chronic obstructive pulmonary disease and pneumonia [88]. A comparison of mortality of statin users $(\mathrm{n}=228,528)$ versus nonstatin users $(\mathrm{n}=1,261,938)$ in the United States veteran population revealed a highly significant increase in survival rate [89]. Almost half of statin users had started the therapy at the age of 70 years or older, and the conclusion was that the therapy is an effective strategy for promoting longevity.

Niacin added to statin therapy regressed atherosclerosis in carotid arteries as measured by IVUS [90], and a follow-up trial revealed increased survival rate for individuals initially randomized to niacin [58]. Fibrates prevent the progression of coronary atherosclerosis as 
assessed by angiography [58]. A ten-year fibrate therapy for dyslipidemia increased survival rate as compared with dyslipidemic persons without treatment [91], and a follow-up control of the Helsinki Heart study revealed that gemfibrozil reduces CHD mortality, and also total mortality of obese persons with high triglycerides [92]. Cholestyramine therapy had positive effect on coronary atherosclerosis assessed by angiography and it reduced the risk of CHD death and/or nonfatal myocardial infarction [93], and resin therapy, cholestyramine or colestipol, reduced cardiovascular mortality [19].

ACEIs, ARBs and CCBs, drugs indicated for cardiovascular diseases, also have antiatherosclerotic effects. ACEI treatment has been shown to reduce carotid IMT [94] and $A R B$ treatment plaque volume in coronary arteries [95], and CCB therapy to widen the lumen and inhibit the intimal hyperplasia in coronary stent lesions [96]. The antiatherosclerotic effects could contribute to the improved survival rate reported for ACEI- [97] and CCB[98] treated subjects, and to reduced rate of cardiovascular events of ARB-treated individuals [97].

\section{Goals for health promotion}

The effects of healthy lifestyle and pharmacotherapy, the decrease in the incidence of cardiovascular and other diseases and the increase in life expectancy, emphasize the importance of future actions that improve commitment to both healthy living habits and drug therapy, and further on developing of new and more effective and well tolerated drugs and therapies. Poor dietary habits, unhealthy composition of diet with excess calories, inadequate physical activity and adiposity, smoking, and excess stress, are major problems that affect health in modern societies. Hence, the clinical evaluation and treatment of dietary, physical activity, and other living habits must become as routine and familiar as assessment of blood lipid and glucose levels, and blood pressure. It is also important to avoid unhealthy stress and to learn to how to manage it. Effective focusing on life style risk prevents or delays the occurrence of CHD, cardiovascular disease, diabetes mellitus and obesity, and reduces the need of drug therapy or even makes it unnecessary.

The positive effects of gene activators have led to intensive search for new molecules with potential effects on risk factors and effectors in the antiatherogenic metabolic cascade, such as enzymes, receptors and transporters. HDL and its constituents are key therapeutic targets for preventing atherosclerotic lesion formation and promoting the regression of established atherosclerotic lesions [99]. Many P450-inducing compounds increase apo AI, HDL-C and the HDL-C/cholesterol ratio [5,6], and new molecules acting on cholesterol metabolizing P450enzymes in the liver, brain and other tissues are also potentially effective antiatherogenic agents. Investiga- tional agents also include new LXR agonists and PPAR agonists and other HDL elevators, and compounds enhancing the expression of $\mathrm{ABC}$ transporters [74]. The agonists of PXR, which affects the fate of cholesterol, also have potential to activate antiatherogenic mechanisms. The evaluation of the effects of the combinations lifestyle factors and drug treatments and of drug combinations can significantly improve therapeutic possibilities.

\section{Discussion}

The reviewed studies show that living habits and pharmacological compounds upregulate genetic mechanisms that beneficially affect lipoprotein metabolism, promote wellbeing and increase survival. The studies also associate lipoprotein metabolism and $\mathrm{HDL}_{2}$ subclass with the process of living a very long life. The liver is the principal site for the synthesis of lipids and proteins, and changes in hepatic function can significantly affect lipoprotein metabolism and the development of atherosclerotic and other diseases.

The first studies clarifying the effects of genes on hepatic proteins and P450 activity and plasma apolipoprotein and lipoprotein risk factors were performed in the 1970s. Our original observations linked gene activation and $\mathrm{P} 450$ induction with increase in hepatic protein and phospholipid concentration and with cardiovascular risk factor profile that is typical of low risk of atherosclerotic disease [5,6], and that later on has been found typical also for very old people together with decreased incidence of cardiovascular, metabolic and other diseases. A number of gene-activators including statins, niacin, cholestyramine, nifedipine [100], pioglitazone [101] and phenytoin [102], and also alcohol consumption [103], increase $\mathrm{HDL}-\mathrm{C}$ and the large, $\mathrm{PC}$-rich $\mathrm{HDL}_{2}-\mathrm{C}$, and particularly statins, niacin and cholestyramine are effective in reducing cholesterol and LDL-C. $\mathrm{HDL}_{2}-\mathrm{C}$ also rises with ageing and is typical for very old people $[49,52]$.

Several gene-inducing mechanisms are active in the prevention and regression of atherosclerosis. Both lifestyle factors and pharmacological compounds upregulate apo AI and LDLR gene expression and raise HDL-C and and reduce LDL-C, respectively. They similarly activate several genes in the cholesterol elimination pathways, including nuclear receptors, $\mathrm{ABC}$ transporters, and enzymes such as CYPs and CCT $\alpha$. Many gene-activators increase the subfraction $\mathrm{HDL}_{2}$ which has high apo $\mathrm{AI}$ and phospholipid content compared with $\mathrm{HDL}_{3}$, and key role in the antiatherogenic effect of HDL [104]. The individuals with high P450-activity in the liver, show high plasma HDL-C, $\mathrm{HDL}_{2}-\mathrm{C}$ and HDL-C/cholesterol ratio, while a deficient P450-activity leads to cholesterol accumulation, hypercholesterolemia and xanthoma formation and promotes atherogenesis $[11,105]$. The increase of HDL-C 
and $\mathrm{HDL}_{2}-\mathrm{C}$ with increasing hepatic $\mathrm{P} 450$ activity suggests that the cholesterol metabolizing CYPs, that are particularly prevalent in the liver [44], enhance the generation of $\mathrm{OHCs}$ and activation of $\mathrm{HDL}$ and $\mathrm{HDL}_{2}$ raising mechanisms. The relation of plasma HDL-C (Figure 1) $[10,11]$ and liver P450 (Figure 2) [106] to hepatic phospholipids also suggests that the enrichment of PC in $\mathrm{HDL}_{2}$ with increasing $\mathrm{P} 450$ activity reflects the effect of these CYPS on the synthesis of PC, the primary phospholipid of HDL. An effective CYP-mediated OHC generation could induce hepatic CCT $\alpha$ and PC synthesis [29], and consequently increase HDL-C, and particularly the PC-rich $\mathrm{HDL}_{2}$-C. A similar effect of a P450-inducing agent on $\mathrm{OHC}$ production and hepatic $\mathrm{PC}$ synthesis could also have a role in the elevation of HDL-C and $\mathrm{HDL}_{2}-\mathrm{C}$. The studies on CCT $\alpha$-deficient mice showing a decrease of $\mathrm{PC}$ content in the liver, the principal source of $\mathrm{PC}$ in HDL, as well as ABCA1 expression in hepatocytes and marked lowering of HDL-C levels [14], support this possibility. Correspondingly to these effects, a delivery of $\mathrm{CCT} \alpha$ to knock-out mice increased hepatic PC mass and ABCA1 levels, and plasma HDL-C levels in vivo. In agreement with these findings, the high phospholipid content in $\mathrm{HDL}_{2}$ particles has been identified as an efficient driving factor for cholesterol removal from peripheral cells $[107,108]$, and HDL phospholipids correlate

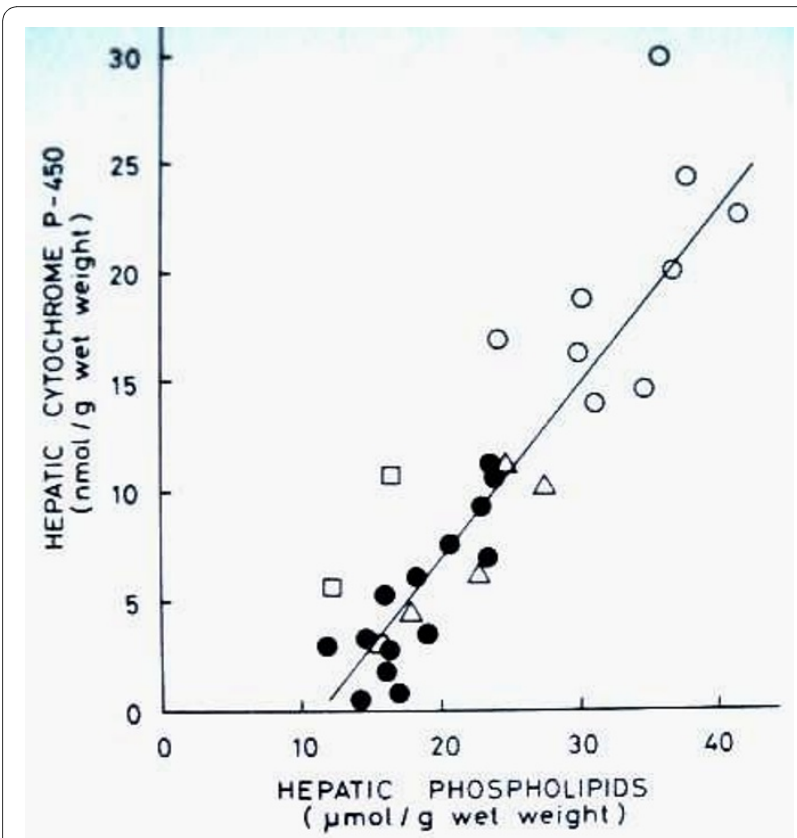

Figure 2 Relationship between cytochrome P450 and phospholipid concentrations in human liver. $\triangle$ patients with normal liver histology, O patients with normal liver but undergoing inducing drug therapy, - patients with fatty liver, $\square$ patients with liver cirrhosis. $r=$ $0.909, p<0.001$ for all subjects. For fatty liver group, $r=0.834, p<0.001$ (Savolainen MJ et al, Eur J Clin Pharmacol. 1985, 27:727-732). inversely with the severity of angiographically defined coronary atherosclerosis [109].

The OHCs mediate the activation of antiatherogenic mechanisms. They upregulate, via LXR, effectors in cholesterol efflux including ABCA1, ABCG1 and apo AI. An elevation of cellular cholesterol upregulates hepatic P450enzymes, OHCs [110], CCT $\alpha$ [29], and ABCA1, and increases plasma HDL-C [111], whereas targeted deletion of hepatic ABCA1 markedly reduces it [112]. Corresponding to this effect, a recent study of Brunham et al. showed that mice lacking hepatic ABCA1 display a significant accumulation of cholesterol in aorta and increase in aortic atherosclerotic lesion area, while a selective deletion of macrophage ABCA1 did not significantly modulate atherogenesis [113]. These studies on hepatic enzymes, mediators, lipids and transporters, and atherosclerosis, emphasize the key role of liver in maintaining cholesterol homeostasis and in the prevention and regression of atherosclerosis.

Gene-activators increasing HDL and apo AI have, in addition to cholesterol efflux and transport, a number of other favorable effects (Table 2) [6,114]. They inhibit inflammatory processes in vascular cells, promote endothelial cell nitric oxide (NO) release and vasodilatation, and have a variety of antioxidative actions. HDL together with PON1 and other enzymes inhibit the atherogenic oxidative modification of LDL in the arterial wall. Other antiatherogenic actions of HDL/apo AI include inhibition of platelet aggregation, stimulation of prostacyclin production and fibrinolysis, and inhibition of expression adhesion molecules and apoptosis of endothelial cells. Interestingly, high plasma HDL and apo $\mathrm{AI}$ also associate with good cognitive performance in very old people $[49,115]$, suggesting that the antiaggregation, anti-inflammatory and antioxidative effects $\mathrm{HDL} /$ apo $\mathrm{AI}$ have a role in this relation.

Table 2: Antiathrogenic effects of HDL/apolipoprotein AI

Efflux and reverse transport of cholesterol

Anti-inflammatory

- inhibition of the expression of vascular cell adhesion molecules

- stimulation of endothelial NO production

Antioxidative

- inhibition of oxidative modification of LDL

Antithrombotic

$$
\begin{aligned}
& \text { - inhibition of platelet aggregation } \\
& \text { - fibrinolysis } \\
& \text { - increase of prostacyclin production }
\end{aligned}
$$

Facilitation of endothelial cell function and repair

Inhibition of apoptosis of endothelial cells 


\section{Conclusions}

The studies performed in the 1970s and thereafter have demonstrated that living habits and pharmacological compounds upregulate genetic mechanisms which act in maintaining cellular homeostasis, have beneficial metabolic and health effects, and enhance longevity. Major findings of the investigations associate gene activation and hepatic protein and phospholipid metabolism with plasma lipoprotein profile, high $\mathrm{HDL}-\mathrm{C}, \mathrm{HDL}_{2}-\mathrm{C}$ and $\mathrm{HDL}-\mathrm{C} /$ cholesterol ratio, that is typical of low risk of cardiovascular and other diseases, and also of exceptional longevity. In addition, high HDL contributes to protection against oxidation, inflammation and thrombosis, and associates with good cognitive function in people of advanced age.

The studies on nuclear receptors, enzymes, phospholipids, proteins and $\mathrm{ABC}$ transporters indicate that the liver has a major role in atheroprotection and regression of atherosclerosis. P450-enzymes, physiological key factors in maintaining cholesterol homeostasis generate oxysterols for the removal of excess cholesterol. Hepatic CCT $\alpha$ is the key enzyme in the synthesis of PC and an important regulator of plasma HDL-C level, and the increased phospholipid mass in $\mathrm{HDL}_{2}$ is an efficient driving factor for cholesterol removal from peripheral cells. Healthy lifestyle choices counteract, via natural gene activation, the atherosclerotic vascular process and increase survival, and gene-activating xenobiotics upregulate mechanisms that produce lipoprotein pattern typical of very old people together with reduced incidence of cardiovascular, metabolic and other diseases. Avoiding unhealthy stress and managing it properly promotes health and increases life expectancy.

The positive effects of living habits and pharmacological compounds on the incidence of cardiovascular, metabolic and other diseases, and life expectancy, emphasize the importance of future activities that increase the adherence to both healthy lifestyle and drug treatment, and further of searching of new, effective and well tolerated agents and therapies.

\footnotetext{
Abbreviations

ABC: ATP-binding cassette; ARB: angiotensin receptor blocker; CCB: calcium channel blocker; CCTa: CTP:phosphocholine cytidylyltransferase-a; CD36: cluster of differentiation 36; DHET: dihydroxyeicosatrienoic acid; EET: epoxyeicosatrienoic acid; HETE: hydroxyeicosatetraenoic acid; HMGCOAR: hydroxymethylglutaryl-coenzyme A reductase; IMT: intima-media thickness; LCAT: lecithin:cholesterol acyltransferase; LXR: liver $X$ receptor; PC: phosphatidylcholine; PPAR: peroxisome proliferator-activated receptor; PXR: pregnane $X$ receptor; SR-B1: scavenger receptor B1; SREBP: sterol regulatory element binding protein
}

\section{Competing interests}

The author declares that he has no competing interests.

\section{Acknowledgements}

The author is grateful for excellent collaboration especially to Eero Sotaniemi [†], Olavi Pelkonen, Markku Savolainen and Vilho Myllylä from the University of Oulu, Finland, Christian Ehnholm from the National Institute of Health and Welfare, Helsinki, and Heikki Vapaatalo from the University of Helsinki. The studies have been supported by the Academy of Finland and the Paavo Nurmi Foundation, Finland.

\section{Author Details}

Institute of Biomedicine, Pharmacology, University of Helsinki, Finland

Received: 12 April 2010 Accepted: 6 July 2010

Published: 6 July 2010

\section{References}

1. Chrousos GP, Kino T: Glucocorticoid signaling in the cell: expanding clinical implications to complex human behavioral and somatic disorders. Ann NY Acad Sci 2009, 1179:153-166.

2. Bonow RO, Smaha LA, Smith SC Jr, Mensah GA, Lenfant C: The international burden of cardiovascular disease: responding to the emerging global epidemic. Circulation 2002, 106:1602-1605.

3. Gordon T, Castelli WP, Hjortland MC, Kannel WB, Dawber TR: High-density lipoprotein as a protective factor against coronary heart disease. Am J Med 1977, 62:707-714

4. Miller NE, Miller GJ: Clinical and Metabolic Aspects of High-density Lipopropteins. Amsterdam: Elsevier; 1984.

5. Luoma PV, Sotaniemi EA, Pelkonen RO, Ehnholm C: Plasma high density lipoprotein and liver microsomal enzyme activity in man. In The Medical Research Council 1977-1979 Edited by: Pilli-Sihvola AS, Laaksovirta T. Helsinki: The Academy of Finland; 1980:71.

6. Luoma PV: Gene activation, apolipoprotein A-I/high density lipoprotein, atherosclerosis prevention and longevity. Pharmacol Toxicol 1997, 81:57-6.

7. Goldstein JL, Brown MS: The LDL receptor. Arterioscler Thromb Vasc Biol 2009, 29:431-438.

8. Rader DJ, Schaefer JR, Lohse P, Ikewaki K, Thomas F, Harris WA, Zech LA Dujovne CA, Brewer HB Jr: Increased production of apolipoprotein A-I associated with elevated plasma levels of high-density lipoproteins, apolipoprotein A-I, and lipoprotein A-I in a patient with familial hyperalphalipoproteinemia. Metabolism 1993, 42:1429-1434.

9. Le NA, Ginsberg HN: Heterogeneity of apolipoprotein Al in turnover in subjects with reduced concentrations of plasma high density lipoprotein cholesterol. Metabolism 1988, 37:614-617.

10. Luoma PV, Sotaniemi EA, Pelkonen RO, Savolainen MJ, Ehnholm C: Induction and lipoproteins. Lancet 1982, 1:625.

11. Luoma PV, Savolainen MJ, Sotaniemi EA, Pelkonen RO, Arranto AJ, Ehnholm C: Plasma high density lipoprotein and liver lipids and proteins in man. Relation to hepatic histology and microsomal enzyme induction. Acta Med Scand 1983, 214:103-109.

12. Rubin EM, Krauss MR, Spangler EA, Verstuyft JG, Clift MS: Inhibition of early atherogenesis in transgenic mice by human apoprotein $A-I$. Nature 1991, 353:265-267.

13. Nissen SE, Tsunoda T, Tucsu EM, Schoenhagen P, Cooper CJ, Yasin M, Eaton GM, Lauer MA, Sheldon WS, Halpern S, Crowe T, Blankenship JC, Kerensky R: Effect of recombinant Apo AI Milano on coronary atherosclerosis in patients with acute coronary syndromes: a randomized controlled trial. JAMA 2003, 290:2292-2300,

14. Jacobs RL, Lingrell S, Zhao Y, Francis GA, Vance DE: Hepatic CTP: phosphocholine cytidylyltransferase- $a$ is a critical predictor of plasma high density lipoprotein and very low density lipoprotein. J Biol Chem 2008, 283:2143-2155

15. Björkhem I, Diczfalusy U: Oxysterols.Friends, foes, or just fellow passengers. Arterioscler Thromb Vasc Biol 2002, 22:734-742.

16. Nebert DW, Russell DW: Clinical importance of the cytochromes P450. Lancet 2002, 360:1155-1162.

17. Pullinger CR, Eng C, Salen G, Shefer S, Barra AK, Erickson SK, Verhagen A, Rivera CR, Mulvihill SJ, Malloy MJ, Kan JP: Human cholesterol 7ahydroxylase (CYP7A1) deficiency has a hypercholesterolemic phenotype. J Clin Invest 2002, 110:109-117. 
18. Miettinen TA, Gylling H: Mortality and cholesterol metabolism in familial hypercholesterolemia. Long-term follow-up of 96 patients. Arteriosclerosis 1988, 8:163-167.

19. Studer M, Briel M, Leimenstoll B, Glass TR, Bucher HC: Effect of different antilipidemic agents and diets on mortality. Arch Int Med 2005, 165:725-730.

20. Chen W, Chen G, Head DL, Mangelsdorf DJ, Russell DW: Enzymatic reduction of oxysterols impairs LXR signaling in cultured cells and the livers of mice. Cell Metab 2007, 5:73-79.

21. Zhao C, Dahlman-Wright K: Liver X receptor in cholesterol metabolism. J Endocrinol 2010, 204:233-240

22. Björkhem I: Are side-chain oxidized oxysterols regulators also in vivo? J Lipid Res 2009, 50:S213-218.

23. Gale SE, Westover EM, Dudley N, Krishnan K, Merlin S, Scherrer DE, Han X, Zhai X, Brockman HL, Brown RE, Covey DF, Schaffer JE, Schlesinger P, Ory DS: Side chain oxysterol regulates cellular cholesterol homeostasis through direct sterol-membrane interactions. J Biol Chem 2009, 284:1755-1764

24. Wong J, Quinn C, Brown AJ: SREBP-2 positively regulates transcription of the cholesterol efflux gene, $A B C A 1$, by generating oxysterol ligands for LXR. Biochem J 2007, 400:485-489.

25. Fleming I: Vascular cytochrome P450 enzymes: Physiology and pathophysiology. TCM 2008, 18:20-24.

26. Spector AA, Norris AW: Action of epoxyeicosatrienoic acids on cellular function. Am J Physiol Cell Physiol 2007, 292:C996-C1012.

27. Spiecker M, Darius H, Hankeln T, Muhidien S, Sattler AM, Schaefer JR, Node K, Börgel J, Mgge A, Lindpainter K, Huesing A, Maisch B, Zeldin DC, Liao JK: Risk of coronary artery disease associated with polymorphism of the cytochrome P450 epoxygenase CYP2J2. Circulation 2004, 110:2132-2136.

28. Ng V, Huang Y, Reddy LM, Falck JR, Lin ET, Kroetz DL: Cytochrome 450 eicosanoids are activators of peroxisome proliferator-activated receptor a. Drug Metab Dispos 2007, 35:1126-1134.

29. Gehrig K, Lagace TA, Ridgway ND: Oxysterol activation of phosphatidylcholine synthesis involves CTP:phosphocholine cytidylyltransferase a translocation to the nucleus. Biochem J 2009, 418:209-217.

30. Rodgers JT, Puigserver P: Fasting-dependent glucose and lipid metabolic response through hepatic sirtuin 1. PNAS 2007, 104:12861-12866

31. Li X, Zhang S, Blander G, Tse JG, Krieger M, Guarente L: SIRT1 deacetylates and positively regulates the nuclear receptor LXR. Mol Cell 2007, 28:91-106.

32. Kim EJ, Um SJ: SIRT1: roles in aging and cancer. BMB Reports 2008 , 41:751-756

33. Feige JM, AuwerX J: DisSirting on LXR and cholesterol metabolism. Cell Metab 2007, 6:343-345.

34. Soran H, Younis NN, Charlton-Menys V, Durrington P: Variation in paraoxonase-1 activity and atherosclerosis. Curr Opin Lipidol 2009 20:265-274

35. Leus FR, Wittekoek ME, Prins J, Kastelein JJP, Voorbij HAM: Paraoxonase gene polymorphisms are associated with carotid arterial thickness in subjects with familial hypercholesterolemia. Atherosclerosis 2000, 149:371-377.

36. Sonoda J, Pei L, Evans RM: Nuclear receptors: Decoding metabolic disease. FEBS Letters 2008, 582:2-9

37. Tontonoz $P$, Mangelsdorf $D J$ : Liver $X$ receptors signalling pathways in cardiovascular disease. Mol Endocrinol 2003, 17:985-993.

38. Duval C, Touche V, Tailleux A, Fruchart JC, Fievet C, Clavey V, Staels B, Lestavel $\mathrm{S}$ : Niemann-Pick $\mathrm{C} 1$ like gene expression is downregulated by LXR activators in the intestine. Biochem Biophys Res Commun 2006, 340:1259-1263.

39. Wang Y, Rogers PM, Su C, Varga G, Stayrook KR, Burris TP: Regulation of cholesterologenesis by the oxysterol receptor LXRa. J Biol Chem 2008 , 283:26332-2639.

40. Rigamonti, Chinetti-Ghaguidi G, Staels B: Regulation of macrophage functions by PPARa, PPARY, and LXRs in mice and men. Arterioscler Thromb Vasc Biol 2008, 28:1050-1059.

41. Sonoda J, Chong LW, Downes M, Barish GD, Liddle C, Lee CH, Evans RM: Pregnane $\mathrm{X}$ receptor prevents hepatorenal toxicity from cholesterol metabolites. PNAS 2005, 102:2198-2203.
42. Li T, Chen W, Chiang JYL: PXR induces CYP27A1 and regulates metabolism in the intestine. J Lipid Res 2007, 48:373-384.

43. Trigatti BL, Krieger M, Rigotti A: Influence of the HDL receptor SR-BI on lipoprotein metabolism and atherosclerosis. Arterioscler Thromb VasC Biol 2003, 23:1723-1738.

44. Oram JF, Vaughan AM: ATP-binding cassette transporter Al: A cell cholesterol exporter that protects against cardiovascular disease. Physiol Rev 2005, 85:1343-1372.

45. Brewer HB Jr, Remaley AT, Neufeld EB, Basso F, Jouce C: Regulation of plasma high-density lipoprotein levels by the ABCA1 transporter and the emerging role of high-density lipoprotein in the treatment of cardiovascular disease. Arterioscler Thromb Vasc Biol 2004, 24:1755-1760.

46. Schmitz G, Langmannn T: Transcriptional regulatory networks in lipid metabolism control ABCA1 expression. Biochim Biophys Acta 2005 1735:1-19.

47. Yokoyama S: HDL biogenesis and cellular cholesterol homeostasis. Ann Med 2008, 40:29-38

48. Westendorp RGJ, van Heemst D, Rozing MP, Frölich MF, Moijaart SP, Blauw GJ, Beekman M, Heijmans BT, de Craen AMJ, Slagboom PE, Leiden Longevity Study Group: Nonagenarian siblings and their offsprings display lower risk of mortality and morbidity than sporadic nonagenarians: The Leiden longevity study. JAGS 2009, 57:1634-1637.

49. Arai $Y$, Hirose N: Aging and HDL metabolism in elderly people more than 100 years old. J Atheroscler Thromb 2004, 11:246-252.

50. Malaguernara M, Giugno I, Ruello P, Rizzo M, Panebianco MP, Pistone G, Tomasello FB: Lipid profile variations in a group of healthy elderly and centenarians. Eur Rev Med Pharmacol Sci 1998, 2:75-79.

51. Suzuki M, Wilcox BJ, Wilcox CD: Implications from and for food cultures for cardiovascular disease: longevity. Asia Pac J Clin Nutr 2001, 10:165-171

52. Barzilai N, Atzmon G, Schechter C, Schaefer EJ, Cupples AL, Lipton R, Chen S, Shuldiner AR: Unique lipoprotein phenotype and genotype associated with exceptional longevity. JAMA 2003, 290:2030-2040

53. Terry DT, Wilcox M, McCormick MA, Lawler E, Perls TT: Cardiovascular advantages among the offspring of centenarians. J Gerontol: Med Sci 2003, 58A:428-431.

54. Barzilai N, Gabriely I, Gabriely M, lankowitz N, Sorkin JD: Offsprings of centenarians have a favorable lipid profile. JAGS 2001, 49:76-79.

55. Dullens SPJ, Plat J, Mensink RP: Increasing apoA-I production as a target for CHD risk reduction. Nutrition Metab \& Cardiovasc Dis 2007, 17:618-628

56. Lamon-Fava S, Diffenderfer MR, Barrett PHR, Buchsbaum A, Nyaku M, Horvath KV, Asztalos BF, Otokozawa S, Ai M, Matthan NR, Lichtenstein AH, Dolonikowski GG, Schaefer EJ: Extended- release niacin alters the metabolism of plasma apoliprotein (apo) A-I and apo-B containing lipoproteins. Arteriosclerosis Thromb Vasc Biol 2008, 28:1672-1678.

57. Mooradian AD, Haas MJ, Wong NCW: The effect of select nutrients on serum high-density lipoprotein cholesterol and apolipoprotein A-I levels. Endocrine Reviews 2006, 27:2-16.

58. Luoma PV: Cytochrome P450 and gene activation - from pharmacology to cholesterol elimination and regression of atherosclerosis. Eur J Clin Pharmacol 2008, 64:841-850

59. Lehrke M, Lebherz C, Millington SC, Guan HP, Milllar J, Rader DJ, Wilson JM, Lazar MA: Diet-dependent cardiovascular lipid metabolism controlled by hepatic LXRa. Cell Metab 2005, 1:297-308.

60. Mozaffarian D, Wilson PWF, Kannel WB: Beyond established and novel risk factors: lifestyle risk factors for cardiovascular disease. Circulation 2008, 117:3031-3038.

61. Kelly RB: Diet and exercise in the management of hyperlipidemia. Am Fam Physician 2010, 81:1097-1102.

62. Trichopoulou A, Costacou T, Bamia C, Trichopoulos D: Adherence to a Mediterranien diet and survival in a Greek population. New Eng/ J Med 2003, 348:2599-2608.

63. Estruh R, Martinez-Gonzalez MA, Corella D, Salas-Salvado J, Ruiz-Gutierrez V, Covas MI, Fiol M, Gomez-Gracia E, Lopez-SAbater MC, Vinyoles E, Aros F, Conde M, Lahoz C, Lapetera J, Saez G, Ros E, PREDIMED Study investigators: Effects of a Mediterranien-style diet on cardiovascular risk factors. A randomized trial. Ann Intern Med 2006, 145:1-11.

64. Mitrou PN, Kipnis V, Thièbaut ACM, Reedy J, Subar AF, Wirfält E, Flood A, Mouw T, Hollenbeck AR, Leitzmann MF, Schatzkin A: Mediterranien dietary pattern and prediction of all-cause mortality in a US population. Arch Int Med 2007, 167:2481-2488. 
65. Leaf DA: The effect of physical exercise on reverse cholesterol transport. Metabolism 2004, 52:950-957.

66. Butcher LR, Thomas A, Backx K, Roberts A, Webb R, Morris K: Low-intensity exercise exerts beneficial effects on plasma lipids via PPAR $\gamma$. Medicine \& Science in Sports \& Exercise 2008, 40:1263-70.

67. Olchawa B, Kingwell BA, Hoang A, Schneider L, Miyazaki O, Nestel P, Sviridoov D: Physical fitness and reverse cholesterol transport. Arterioscler Thromb Vasc Biol 2004, 24:1087-91.

68. Brites F, Verona J, De Geitere C, Fruchart JC, Castro G, Wikinski R: Enhanced cholesterol efflux promotion in well-trained soccer players. Metabolism 2004, 53:1262-1267.

69. Berg A, Frey I, Baumstark MW, Halle M, Keul J: Physical activity and lipoprotein disorders. Sports Med 1994, 17:6-21.

70. Wilund KR, Feeney LA, Tomayko EJ, Chung HR, Kim K: Endurance exercise training reduces gallstone development in mice. J Appl Physiol 2008, 104:761-765.

71. Matthews CE, Jurj AL, Shu X, Li HL, Yang G, Li Q, Gao YT, Zheng W: Influence of exercise, walking, cycling, and overall nonexercise physical activity in mortality in Chinese women. Amer J Epidemiol 2007, 165:1343-1350.

72. Rosengren A, Wilhelmsen L: Physical activity protects against coronary death and death from all causes in middle-aged men. Evidence from a 20-year follow-up of the primary prevention study in Göteborg. Ann Epidemiol 1997, 7:69-75.

73. Kuningas M, Mooijart SP, van Heemst D, Zwaan BJ, Slagboom PE, Westendorp GJ: Genes encoding longevity: from model organisms to humans. Aging Cell 2008, 7:270-280

74. Luoma PV: Gene-activators prevent and regress atherosclerosis and reduce mortality. Cardiovasc Hematol Agents Med Chem 2009, 7:295-304.

75. Asztalos BF, Le Maulf F, Dallal GE, Stein E, Jones PH, Horvath KV, McTaggart $F$, Schaefer EJ: Comparison of the effects of high doses of rosuvastatin versurs atorvastatin on the subpopulations of high-density lipoproteins. Am J Cardiol 2007, 99:681-685.

76. Hsu MH, Savas Ü, Griffin KJ, Johnson EF: Regulation of human cytochrome P450 4F2 expression by sterol regulatory element-binding protein and lovastatin. J Biol Chem 2007, 282:5225-5236.

77. Tamehiro N, Shigemoto-Mogami Y, Kakeya T, Okuhira K, Suzuki K, Sato S, R , Nagao T, Nishimaki-Mogami T: Sterol regulatory element-binding protein- 2 and liver $X$ receptor-driven dual promoter regulation of hepatic $A B C$ transporter $A 1$ gene expression. Mechanism underlying the unique response to cellular cholesterol status. J Biol Chem 2007, 282:21090-9.

78. Rubic T, Trottmann M, Lorenz RL: Stimulation of CD36 and the key effector of reverse cholesterol transport ATB-binding cassette A1 in monocytoid cells. Biochem Pharmacol 2004, 67:411-419.

79. Shepherd J, Packard CJ, Patsh JR, Gotto AM Jr, Taunton OD: Effects of nicotinic acid therapy on plasma high density lipoprotein subfraction distribution and composition and on apolipoprotein A metabolism. J Clin Invest 1979, 63:858-867.

80. McKenney JM, Jones PH, Bays HE, Knopp RH, Kashyap ML, Ruoff GE, MCGovern ME: Comparative effects on lipid levels of combination therapy with a statin and extended-release niacin or ezetimibe versus statin alone (the COMPELL study). Atherosclerosis 2007, 192:432-437.

81. Shepherd J, Packard CJ: High density apolipoprotein metabolism. In Clinical and Metabolic Aspects of High-density Lipopropteins Edited by: Miller NE, Miller GJ. Amsterdam: Elsevier; 1984:247-274.

82. Rudling M, Angelin B, Ståhle L, Reihnèr E, Sahlin S, Olivecrona H, Björkhem I, Einarsson C: Regulation of hepatic low-density lipoprotein receptor, 3hydroxy-3-methylglutaryl coenzyme A reductase, and cholesterol 7ahydroxylase mRNAs in human liver. J Clin Endocrinol Metab 2002, 87:4307-4313

83. Toi T, Taguchi I, Yoneda S, Kageyama M, Kikuchi A, Tokura M, Kanaya T, Abe S, Matsuda R, Kaneko N: Early effect of lipid-lowering therapy with pitavastain on regression of coronary atherosclerotic plaque comparison with atorvastatin. Circ J 2009, 73:1466-1472

84. Nasu J, Tsuchikane E, Katoh O, Tanaka N, Kimura M, Ehara M, Kinoshita Y, Matsubara T, Matsuo H, Asakura K, Asakura Y, Terashima T, Takayama T, Honey J, Hirayama A, Saito S, Suzuki T: Effect of fluvastatin on progression of coronary atherosclerotic plaque evaluated by virtual histology ultrasound. JACC Cardiovasc Interv 2009, 2:689-696.

85. Tani S, Nagao K, Anazawa T, Kawamata H, Furuya S, Takahashi H, Tida K, Matsumoto M, Washio T, Kumabe N, Hirayama A: Association of leucocyte subtype counts with coronary atherosclerotic regression following pravastatin treatment. Am J Cardiol 2009, 104:464-469.

86. Nicholls SJ, Murat E, Sipahi I, Grasso AW, Schoenhagen P, Hu T, Wolski K, Crowe T, Desai MY, Hazen SL, Kapadia SR, Nissen SE: Statins, high- density lipoprotein cholesterol and regression of coronary atherosclerosis. JAMA 2007, 297:499-508.

87. Brugts JJ, Yetgin T, Hoeks SE, Gotto AM, Shepherd J, Westendorp RGJ, de Craen AJM, Knopp RH, Nakamura H, Ridker P, van Domburg R, Deckers JW: The benefits of statins in people without established cardiovascular disease but with cardiovascular risk factors: metaanalysis of randomized controlled trials. BMJ 2009, 338:b2376.

88. Ishida W, Kajiwara T, Ishii M, Fujiwara F, Taneichi H, Takebe N, Takahahi K, Kaneko Y, Segawa I, Inoue H, Satoh J: Decrease in mortality rate of chronic obstructive pulmonary disease (COPD) with statin use: A population-based analysis in Japan. Tohoku J Exp Med 2007, 212:265-273.

89. Mehta JL, Bursac Z, Hauer-Jensen M, Fort C, Fink LM: Comparison of mortality rates in statin users versus nonstatin users in a United States veteran population. Am J Cardiol 2006, 98:923-928.

90. Taylor AJ, Villines TC, Stanek EJ, Devine PJ, Griffen L, Miller M, Weissman NJ, Turco M: Extended-release niacin or ezetimibe and carotid intimamedia thickness. N Engl J Med 2009, 361:2113-2122.

91. Gardette V, Bongard V, Dallongeville J, Arveiler D, Bingham A, Ruidavets J.B, Amouyel P, Haas B, Ducimetièr P, Ferrières J: Ten - year all-cause mortality in presumably healthy subjects on lipid-lowering drugs (from the Prospective Epidemiological Study of Myocardial Infarction [Prime] prospective cohort). Am J Cardiol 2009, 103:381-386.

92. Tenkanen L, Mänttäri M, Kovanen PT, Virkkunen H, Manninen V: Gemfibrozil in the treatment of dyslipidemia. An 18-year mortality follow-up of the Helsinki Heart Study. Arch Intern Med 2006, 166:743-748.

93. Watts GF, Lewis B, Brunt JNH, Lewis ES, Coltart DJ, Smith LD, Mann JI, Swan $\mathrm{AV}$ : Effects on coronary artery disease of lipid lowering diet, or diet plus cholestyramine. In St Thomas Atherosclerosis Regression Study (STARS). Lancet 1992, 339:563-539.

94. Sonoda M, Aoyagi T, Takenak K, Uno K, Nagai R: A one-year study of the antiatherosclerotic effect of the angiotensin-II receptor blocker Losartan in hypertensive patients. Int Heart J 2008, 49:95-103.

95. Waseda K, Ozaki Y, Takashima H, Junya A, Yasukawa T, Ismail TF, Hishida H, Takayuki I: Impact of angiotensin II receptor blockers on the progression and regression of coronary atherosclerosis. An intravascular ultrasound study. Cir J 2006, 70:1111-1115.

96. Yamazaki T, Taniguchi I, Kurusu T, Shimazu Y, Hashizume Y, Takikawa K, Kuwata M, Onodera T, Yoshikawa M, Mochizuki S: Effect of amlopidine on vascular responses after coronary stenting compared with an angiotensin-converting enzyme inhibitor. Circ J 2004, 68:328-333.

97. Baker WL, Coleman Cl, Kluger J, Reinhart KM, Talati R, Qercia R, Phung OJ, White CM: Systematic review: comparative effectiness of angiotensinconverting enzyme inhibitors or angiotensin receptor blockers for ischemic heart disease. Ann Int Med 2009, 151:861-871.

98. Costanzo P, Perrone-Filardi P, Petretta M, Marciano C, Vassallo E, Gargiulo P, Paolillo S, Petretta A, Chiariello M: Calcium channel blockers and cardiovascular outcomes: a meta-analysis of 175634 patients. $J$ Hypertens 2009, 27:1136-1151.

99. Tabet F, Rye KA: High-density lipoproteins, inflammation and oxidative stress. Clin Science 2009, 116:87-98.

100. Houston MC, Olafsson L, Burger MC: Effects of nifedipine GITS and atenolol monotherapy on serum lipids, blood pressure, heart rate, and weight in mild to moderate hypertension. Angiology 1991, 42:681-690.

101. Lawrence JM, Stirling C, Reid J, Reckless JPD, Taylor GJ: Favorable effect of pioglitazone and metformin compared with gliclazide on lipoprotein subfractions in overweight patients with early type 2 diabetes. Diabetes Care 2004, 27:41-46

102. Miller M, Burgan RG, Osterlund L, Segrest JP, Garber DW: A prospective trial of phenytoin in nonepileptic subjects with reduced $\mathrm{HDL}$ cholesterol. Arterioscler Thromb Vasc Biol 1995, 15:2151-2156.

103. Schaefer C, Parlesak A, Eckoldt J, Bode C, Bode JC, März W, Winkler K Beyond HDL-cholesterol increase: phospholipid enrichment and shift from $\mathrm{HDL}_{3}$ to $\mathrm{HDL}_{2}$ in alcohol consumers. J Lipd Res 2007, 48:1550-8.

104. Miller NE, Hammett F, Saltissi S, Rao S, van Zeller H, Coltart J, Lewis B: Relation of angioraphically defined coronary artery disease to plasma 
lipoprotein subfractions and apolipoproteins. Brit Med J 1981, 282:1741-1744.

105. Luoma PV: Cytochrome P450 - physiological key factor key factor against cholesterol accumulation and the atherosclerotic vascular process. Ann Med 2007, 39:359-370

106. Savolainen MJ, Arranto AJ, Hassinen IE, Luoma PV, Pelkonen RO, Sotaniemi EA: Relationship between lipid composition and drug metabolizing capacity of human liver. Eur J Clin Pharmacol 1985, 27:727-732.

107. Gelissen IC, Harris M, Rye KA, Quinn C, Brown AJ, Kockx M, Cartland S, Pachianatham M, Kritharides $L$, Jessup W: $A B C A 1$ and $A B C G 1$ synergize to mediate cholesterol export to apoA-I. Arterioscler Thromb Vasc Biol 2006, 26:534-540

108. Mäkelä SM, Jauhiainen M, Ala-Korpela M, Metso J, Lehto TM, Savolainen $\mathrm{MJ}$, Hannuksela ML: $\mathrm{HDL}_{2}$ of heavy alcohol drinkers enhances cholesterol efflux from raw macrophages via phospholipid - rich $\mathrm{HDL}_{2 \mathrm{~b}}$ particles. Alcoholism: Clin Exper Res 2008, 32:991-1000.

109. Hsia SL, Duncan R, Schob AH, Chakko SC, Mulingtabang R, He JL, Perez $\mathrm{GO}$ : Serum levels of high-density lipoprotein phospholipids correlate with severity of angiographically defined coronary disease. Atherosclerosis 2000, 152:469-473.

110. Saucier SE, Kandutsch AA, Gayen AK, Swahn DK, Spencer TA: Hydroxycholesterol regulators of 3-hydroxy-3-methylglutaryl-CoA reductase in liver. Effect of dietary cholesterol. J Biol Chem 1989, 264:6863-6869.

111. Wellington CL, Walker EKY, Suarez A, Kwok A, Bissada N, Singaraja R, Yang YZ, Zhang LH, James E, Wilson JE, Francone O, Mcmanus BM, Hayden MR: ABCA1mRNA and protein distribution patterns predict multiple different roles and levels of regulation. Lab Invest 2002, 82:273-283.

112. Timmins JM, Lee JY, Boydyguina E, Kluckman KD, Brunham LR, Mulya A, Gebre AK, Coutinho JM, Colvin PL, Smith TL, Hayden MR, Meda N, Parks JS: Targeted inactivation of hepatic Abca1 causes profound hypoalphalipoproteinemia and kidney catabolism of apoA-I. J Clin Invest 2005, 115:1333-1342.

113. Brunham LR, Singaraja RR, Duong M, Timmins JM, Fievet C, Bissada N, Kang MH, Samra A, Fruchart JC, Mcmanus B, Staels B, Parks JS, Hayden MR: Tissue-specific roles of $A B C A 1$ influence susceptibility to atherosclerosis. Arterioscler Thromb Vasc Biol 2009, 29:548-554.

114. Barter P: HDL: a recipe for longevity. Atherosclerosis Supplements 2004, 5:25-31

115. Atzmon G, Gabriely I, Greiner W, Davidson D, Schechter C, Barzilai N: Plasma HDL levels correlate with cognitive function in exceptional longevity. J Gerontol: Med Sci 2002, 57A:M712-M715.

doi: $10.1186 / 1476-511 X-9-67$

Cite this article as: Luoma, Gene activation regresses atherosclerosis, promotes health, and enhances longevity Lipids in Health and Disease 2010, 9:67

\section{Submit your next manuscript to BioMed Central} and take full advantage of:

- Convenient online submission

- Thorough peer review

- No space constraints or color figure charges

- Immediate publication on acceptance

- Inclusion in PubMed, CAS, Scopus and Google Scholar

- Research which is freely available for redistribution

Submit your manuscript at www.biomedcentral.com/submit
C Biomed Central 